\title{
Investigation of transition between spark ignition and controlled auto-ignition combustion in a V6 direct-injection engine with cam profile switching
}

\author{
N Kalian ${ }^{1 *}$, H Zhao ${ }^{1}$, and J Qiao ${ }^{2}$ \\ ${ }^{1}$ Department of Engineering and Design, Brunel University, Uxbridge, UK \\ ${ }^{2}$ Jaguar Ltd, UK
}

The manuscript was received on 22 February 2008 and was accepted after revision for publication on 18 June 2008.

DOI: 10.1243/09544070JAUTO846

\begin{abstract}
Controlled auto-ignition (CAI) combustion, also known as homogeneous charge compression ignition (HCCI), can be achieved by trapping residuals with early exhaust valve closure in a direct-fuel-injection in-cylinder four-stroke gasoline engine (through the employment of low-lift cam profiles). Because the operating region is limited to low-load and midload operation for CAI combustion with a low-lift cam profile, it is important to be able to operate spark ignition (SI) combustion at high loads with a normal cam profile. A 3.01 prototype engine was modified to achieve CAI combustion, using a cam profile switching mechanism that has the capability to switch between high- and low-lift cam profiles. A strategy was used where a high-lift profile could be used for SI combustion and a low-lift profile was used for CAI combustion. Initial analysis showed that for a transition from SI to CAI combustion, misfire occurred in the first CAI transitional cycle. Subsequent experiments showed that the throttle opening position and switching time could be controlled to avoid misfire. Further work investigated transitions at different loads and from CAI to SI combustion.
\end{abstract}

Keywords: controlled auto-ignition, transitioning, cam profile switching, direct injection, variable valve timing

\section{INTRODUCTION}

Controlled auto-ignition (CAI) combustion, also known as homogeneous charge compression ignition (HCCI), is a process that has the potential to improve both the efficiency and the emissions of internal combustion engines [1]. Perhaps the single largest attraction of CAI (or HCCI) combustion is that it can reduce emissions of nitrogen oxides $\left(\mathrm{NO}_{x}\right)$ by $90-98$ per cent $[\mathbf{2}-\mathbf{5}]$. CAI combustion is achieved by controlling the temperature, pressure, and composition of the fuel-air mixture so that it spontaneously ignites in the engine. This unique characteristic of CAI allows the combustion of very lean or diluted mixtures, resulting in low combustion temperatures that dramatically reduce the engine-out

*Corresponding author: Department of Engineering and Design, Brunel University, Uxbridge, Middlesex, UB8 3PH, UK. email: navin_kalian@yahoo.co.uk
$\mathrm{NO}_{x}$ emissions. As it has no throttling losses, the part-load fuel economy of a gasoline engine can be improved significantly, thus allowing a four-stroke gasoline engine to achieve a 20 per cent reduction in fuel consumption [6]. Various methods have been used to achieve CAI (or HCCI) combustion, principally as follows:

(a) direct intake charge heating;

(b) higher compression ratios;

(c) more auto-ignitable fuel;

(d) recycling of burned gases.

A method that offers a greater degree of flexibility in achieving CAI combustion is the use of internal exhaust gas recirculation (EGR) and trapping of burned gases during the negative valve overlap (Fig. 1). With this method, the exhaust valve is closed early and a volume of exhaust gas is trapped; the intake valve is opened late, preventing blow-back in the intake manifold [7]. The more advanced the 


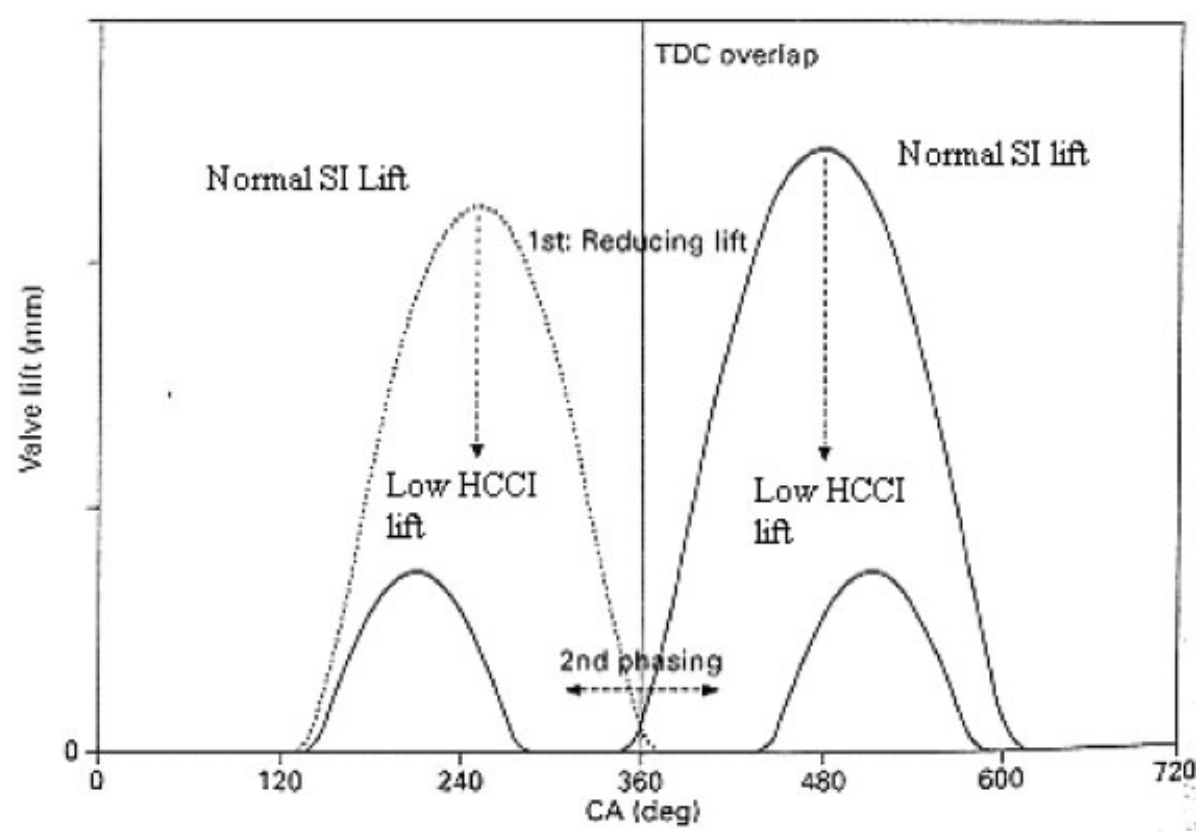

Fig. 1 Diagram showing the valve configurations for low- and high-lift operation

exhaust valve closing (EVC), the greater is the volume of trapped residual. Investigators involved in the 4SPACE [8] project realized this combustion process of gasoline at the part-load, low-speed range of the engine using fixed camshafts, but with a shorter than normal valve opening duration and a lower than normal valve lift. They used the term CAI combustion, which has become a synonym for HCCI combustion, i.e. combustion generated by trapping residuals, which is used in the work described in this paper.

The main drawback of CAI combustion is the limited operating region, and hence various methods have been used to enlarge the CAI operational region [3, 9-11]. Indeed, to operate through a large load range and to ultilize CAI combustion, an engine has to be developed that can switch between spark ignition (SI) high-load operation and CAI low-load to midload operation.
Many researchers [12-14] have developed such an engine with a cam profile switching (CPS) mechanism that allows operation with two different valve lift modes. Furthermore, a variable valve timing (VVT) mechanism is also used to phase the valve timing. The components of the CPS mechanism are, typically, inner and outer coaxial bucket tappets and three cam lobes per engine valve (Fig. 2). The outer cam lobes provide high-lift operation, whereas the inner cam lobe provides low-lift operation. To achieve profile switching, from the outer cam profile to the inner cam profile, the valves within a chosen cylinder are switched by releasing the locking pins and allowing the inner and outer tappets to slide relative to each other, so that high- and low-valve-lift operation can be achieved [15].

Koopmans et al. [16] used an electromechanical camless valve actuation system to undertake SI-CAI-

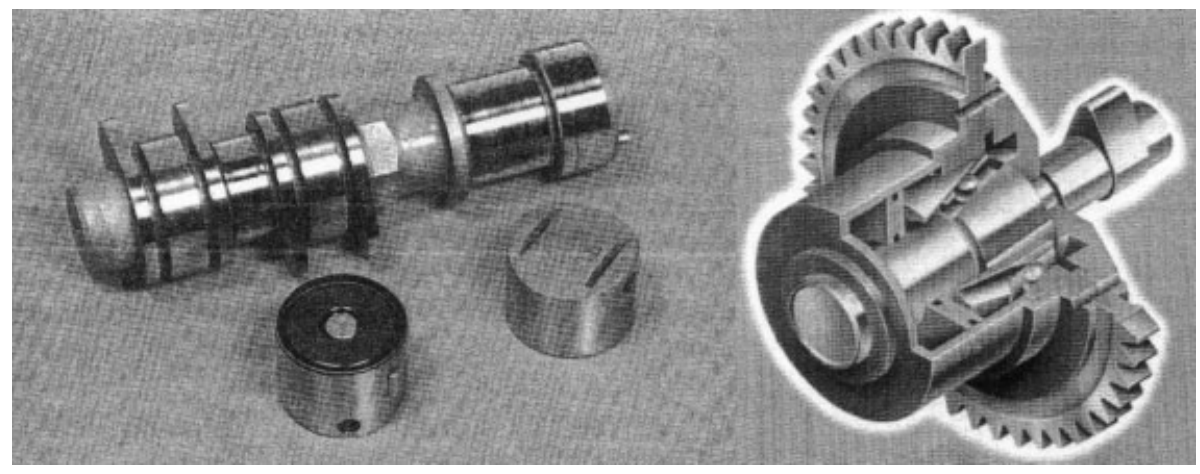

Fig. 2 Picture of the CPS mechanism and VVT mechanism [15] 
SI transitions. They state that, when it is necessary to change from SI to CAI engine operation, the residual mass has to be increased and the air excess ratio and fuel amount often also have to change. Koopmans et al. showed that it is possible to change between SI-CAI-SI modes. With the proper setting of the control parameters of the camless system, no problems with the mode change are encountered. For the mode switch from SI to CAI, the gain in fuel conversion efficiency has to be known or predicted in order to adjust the fuel flow and to avoid a torque jump.

Zhang et al. [17] also studied SI-CAI switching and stated that, to meet the demands (at) different operating conditions, effective control over the incylinder residual gas is needed, in order to achieve dynamic transitions between CAI and SI. Zhang et al. demonstrated that using a four-variable-valve actuating system (4VVAS) with variable valve lift that dynamic transitions from CAI to SI can be achieved. Furthermore, through dynamic management of residual gas and the design of the hybrid heat release curves that smooth transitions from SI to CAI can be achieved. However, the transition is carried out from unthrottled SI operation to unthrottled CAI operation.

Cairns et al. [18] undertook work involving twostage CPS to transition between SI and CAI combustion in a four-cylinder direct-injection (DI) research engine. They found that, in order to avoid individual cylinder misfires, it was necessary to employ sequential CPS strategies. Furthermore, they stated that, to improve the response of the switching tappets, they had to minimize oil circuit dead volumes and to decrease the inlet and exhaust tappet oil supply pressures to the minimum value possible for robust SI operation (about 1 barg). Following these modifications, it was possible to achieve transition without misfire.

In this work, two-stage camshaft and CPS tappets in a V6 DI gasoline engine are used to achieve CAI operation through negative valve overlap of low-lift cam profiles and to resume SI operation using the normal high-lift cam profiles. The operating characteristics of low-lift CAI operation are first presented. The main body of the paper is concerned with the transition between SI and CAI operation.

\section{ENGINE SET-UP}

A 3.01 prototype engine with six cylinders, 24 valves, and double overhead cams (Table 1) was modified to achieve CAI. The cylinder block was based on a standard Jaguar 3.01 S-type engine. The cylinder
Table 1 Jaguar test engine specification

\begin{tabular}{ll}
\hline Engine type & 4 valves per cylinder, V6 \\
\hline Bore $(\mathrm{mm})$ & 89 \\
Stroke $(\mathrm{mm})$ & 79.5 \\
Crank radius $(\mathrm{mm})$ & 38.1 \\
Displacement $\left(\mathrm{cm}^{3}\right)$ & 2967 \\
Compression ratio & 11.3 \\
Fuel supply & $\mathrm{DI}$ \\
Fuel rail pressure & $10 \mathrm{MPa}$ \\
Fuel & Gasoline 95 research octane number \\
Water temperature & $90{ }^{\circ} \mathrm{C}$ \\
$\lambda$ & 1.0 \\
\hline
\end{tabular}

head was modified to incorporate a VVT and a CPS system on both the intake and the exhaust side (Fig. 3). The low-lift cam profile of $2 \mathrm{~mm}$ maximum lift was employed for both the intake and the exhaust valves. The valve opening duration was restricted to $120^{\circ}$ crank angle (CA) for the intake duration and $120^{\circ}$ CA for the exhaust duration for the low-lift operation. The fuel was supplied via a low-pressure fuel pump at 9 bar, before it was pressurized at 100 bar by a high-pressure fuel pump and directly injected into the cylinders. Speed control and load control were achieved by coupling the engine to an eddy-current water-cooled dynamometer.

The engine was controlled using the real-time software, dSPACE (dSPACE GmbH, Paderborn, Germany), which interfaced with a Simulink (The MathWorks, Inc., Natick, Massachusetts, USA) model. Figure 4 shows the schematic diagram for the control and data acquisition system. Using the con-

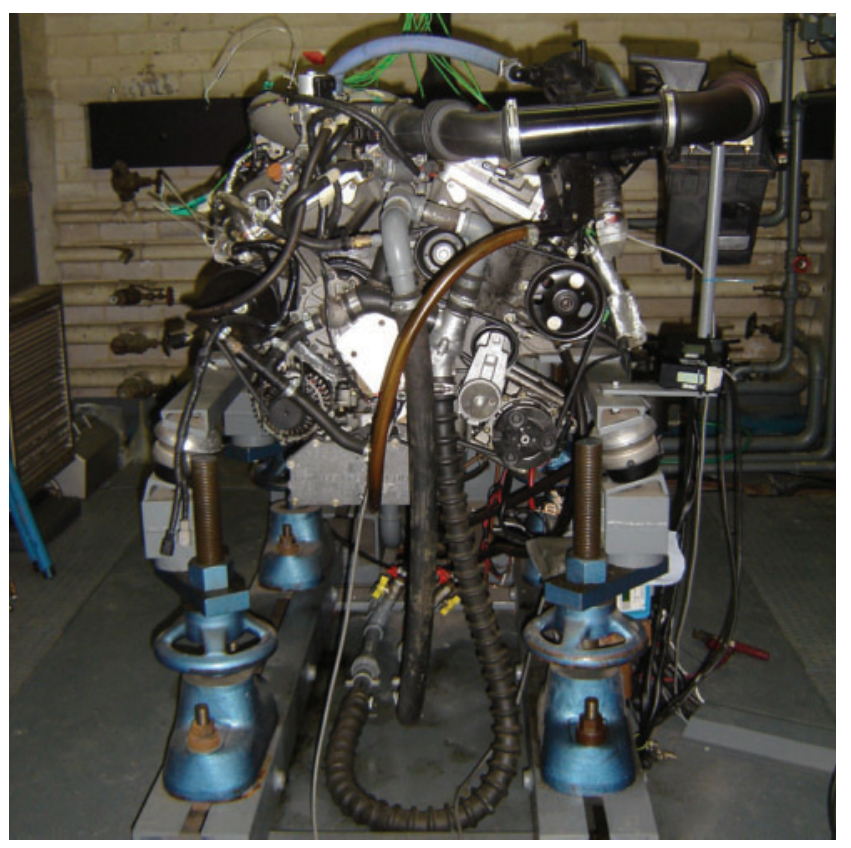

Fig. 3 Photograph of a prototype engine with CPS capabilities 


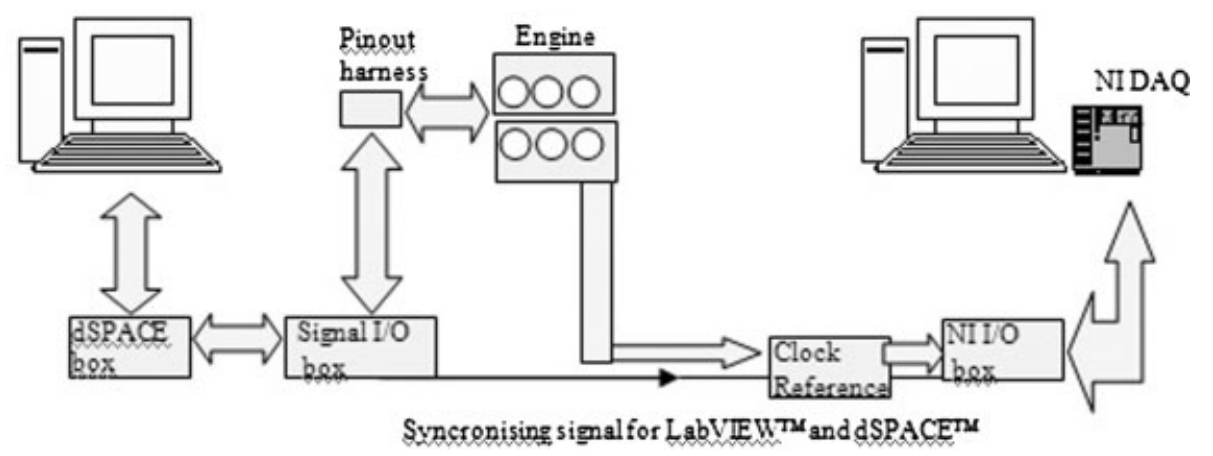

Fig. 4 Control and measurement set-up for the experimental engine

trol program, the following parameters could be controlled: ignition timing, injection timing, air-tofuel ratio, intake and exhaust valve timings, and highand low-lift transitioning. Furthermore, the control program was developed to control injection timing, ignition timing, and valve timing independently for both high-lift and low-lift operations, allowing these parameters to be preset for each transition.

A Kistler 6052B pressure transducer, mounted on bank B, cylinder 3, was used to acquire in-cylinder pressure measurements. A LabVIEW-based data acquisition system (National Instruments, Austin, Texas, USA) was used to calculate the net indicated mean effective pressure (NIMEP), and 10 per cent, 50 per cent, and 90 per cent mass fraction burned (MFB). MS Excel (Microsoft Corporation, Redmond, Washington, USA) was used to calculate the percentages of trapped residual and incremental heat release.

The test engine was started in the high-lift SI combustion mode with a positive valve overlap configuration with ignition timing $325^{\circ} \mathrm{CA}$ after top dead centre (ATDC) (intake), throttle of 8 per cent, speed restricted to $1500 \mathrm{r} / \mathrm{min}$, and start of ignition (SOI) set at mid-intake. The engine was run until the coolant temperature reached $90{ }^{\circ} \mathrm{C}$, at which transition to low-lift operation was possible. A thermostat maintained the engine temperature between 90 and $95{ }^{\circ} \mathrm{C}$. On transition to low lift, the following parameters were set: ignition timing, $340^{\circ}$ CA ATDC; speed maintained at $1500 \mathrm{r} / \mathrm{min}$; SOI set at very early intake; valve timing set in a negative valve overlap configuration. It was found that the ignition timing had no effect on CAI operation at the chosen valve timings; however, a spark was kept on during testing. Table 2 summarizes the test conditions.

\section{RESULTS AND DISCUSSION}

\subsection{CAI operation range at $1500 \mathrm{r} / \mathrm{min}$ and $\lambda=1.0$}

Initial work concentrated on establishing the operational load range for the low-lift cam profiles. For an engine operating in high-lift SI mode, conventional load-speed maps are produced. However, for CAI combustion achieved through exhaust trapping, the load is determined by the EVC time. Therefore, maps incorporating valve timings are produced at each engine speed as a representation of the load range of a CAI engine. Figures 5 and 6 show maps of EVC versus intake valve opening (IVO) plotted for brake mean effective pressure (BMEP) and indicated mean effective pressure (IMEP) for low-lift operation. The BMEP values vary from 1.16 bar to 2.59 bar, and the IMEP values vary from 2.40 bar to 3.67 bar. It can be seen that, as EVC timing is advanced, the BMEP and IMEP values decrease because of increased trapping of exhaust residuals.

\subsection{SI (low load) to HCCI (midload) combustion}

During the preliminary investigation of the transition from SI to CAI combustion, it was found that the air-to-fuel ratio could become extremely lean. However, during the transition period when the throttle is forced to open fully, some of the cylinders in a multi-

Table 2 List of conditions used for testing

\begin{tabular}{lllll}
\hline Mode & Valve timing & Injection timing $\left({ }^{\circ}\right.$ CA ATDC) & Ignition timing $\left({ }^{\circ}\right.$ CA ATDC) & $\begin{array}{l}\text { Speed } \\
(\mathrm{r} / \mathrm{min})\end{array}$ \\
\hline High lift & Positive valve overlap configuration & Mid-intake & 325 & 1.0 \\
Low lift & Negative valve overlap configuration & Very early intake & 340 & 1500 \\
\hline
\end{tabular}




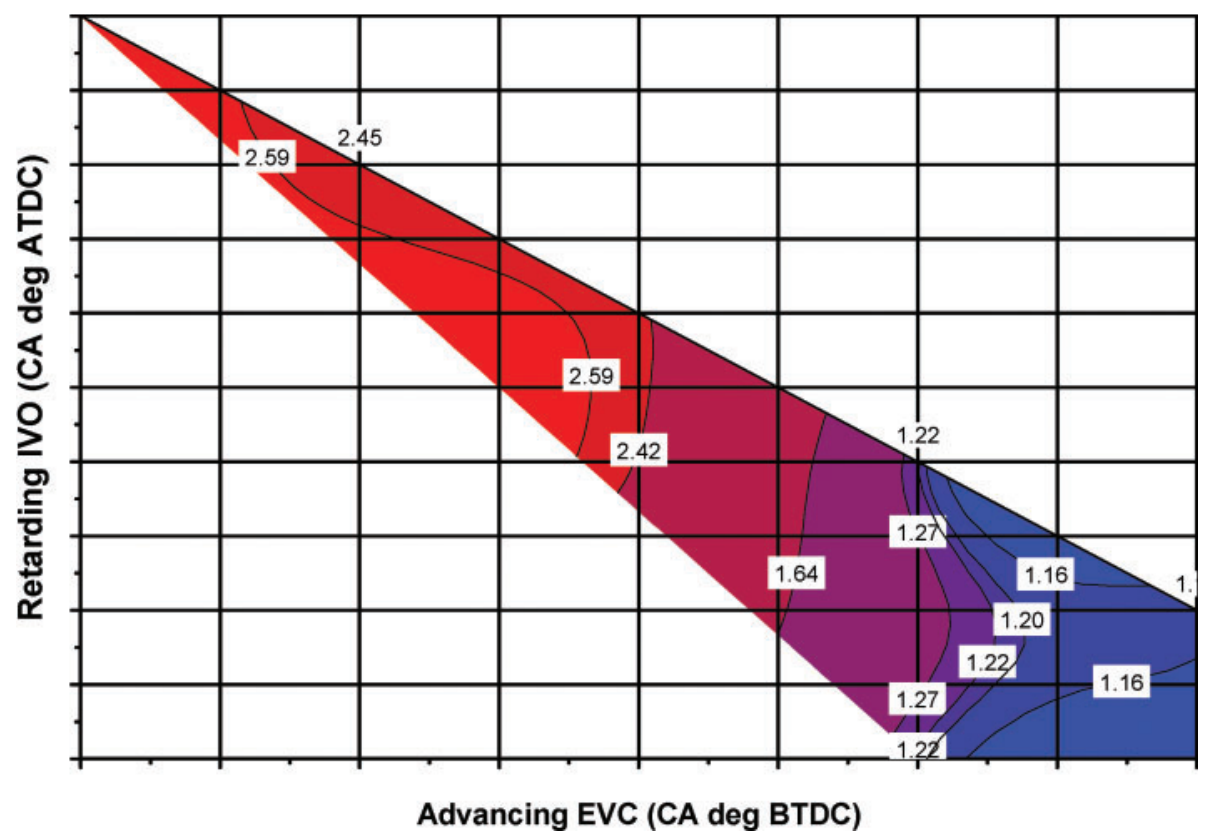

Fig. 5 BMEPs (bar) for different EVC versus IVO curves for low-lift camshafts at $1500 \mathrm{r} / \mathrm{min}$ and $\lambda=1.0$

cylinder (such as the V6 configuration used in the present study) will still be operating in the SI mode before the valve lift is changed. The sudden opening of the throttle leads to very lean mixtures and misfire in those cylinders. Therefore, it was determined that a step function would be used to vary the rate of throttle opening during the transition from a highlift SI mode to a low-lift CAI mode. The step function determined the rate at which the throttle opened and the final throttle opening position. Figure 7 shows the step function used during the transition; the value $t$ was the time in milliseconds at which the throttle was kept at the initial throttle position once the transition signal had been sent. The value $i$ is the time that it takes for the motor to move the throttle from the initial position to the final position.

\subsubsection{Effects of throttle opening}

Figure 8 shows the NIMEP value of cylinder 3 on the bank $B$ side determined from the in-cylinder pressure measurement. It can be observed that a

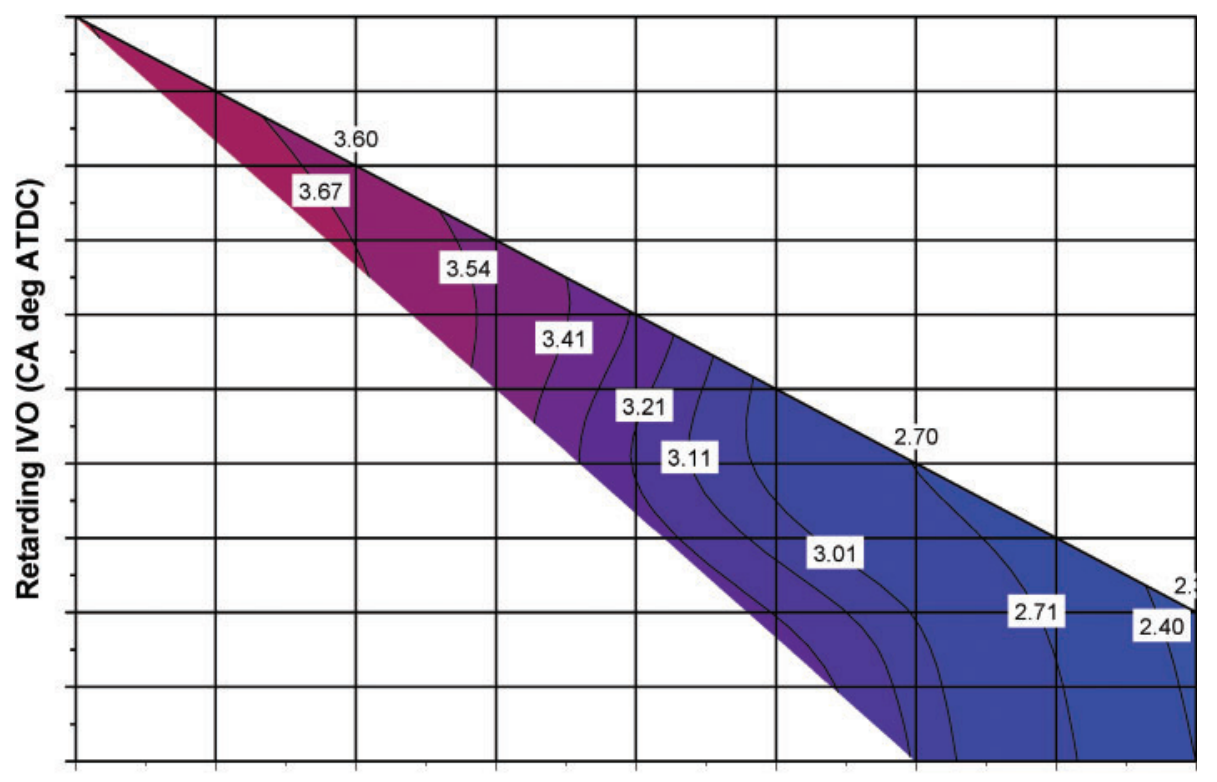

Advancing EVC (CA deg BTDC)

Fig. 6 IMEPs (bar) for different EVC versus IVO curves for low-lift camshafts at $1500 \mathrm{r} / \mathrm{min}$ and $\lambda=1.0$ 


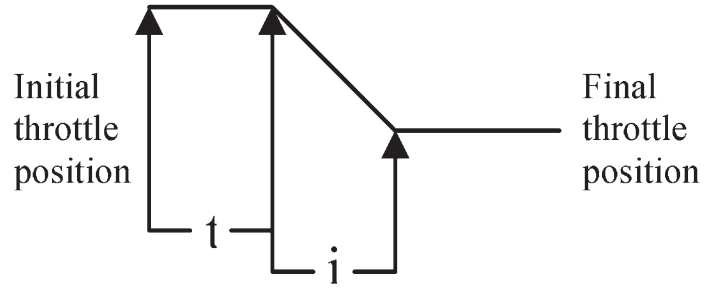

Fig. 7 Step function used during the transition

transition from high-lift but throttled SI combustion at low load to low-lift CAI combustion at higher load causes misfire in the first transitional cycle for opening to 100 per cent and 30 per cent throttle. From Fig. 8, it can be seen that, when the throttle is opened to the wide-open throttle (WOT) position during the SI-CAI transition, a complete misfire occurs. Opening to 30 per cent position or more also causes a misfire. In effect, 30 per cent throttle position induces as much air as 100 per cent throttle since the reduced intake lift is the main limiting factor for the volume of air inducted. When the throttle position is limited to 20 per cent, there is still a fluctuation in the NIMEP, but at a much reduced magnitude. The NIMEP drops from about 2.25 bar, during SI operation, to 1.5 bar during the first cycle of CAI operation, and then stabilizes at 2.5 bar for CAI operation.

On further inspection of the pressure trace during transitioning for WOT CAI (Fig. 9), it can be seen that the drop in NIMEP is caused by two factors. First, it appears that the onset of low exhaust valve lift and, hence, early EVC causes a huge recompression pressure during the negative valve overlap period in the first transition cycle. This imposes a significant increase in the pumping losses (Fig. 10) and, hence, lower NIMEP value. Second, the first cycle of CAI combustion is characterized by a much lower cylinder pressure. The peak pressure during the first CAI cycle is 24 bar compared with the consequent cycles where the peak pressure reaches 39 bar. For opening to 20 per cent throttle for CAI combustion (Fig. 11), the peak pressure in the first CAI cycle is 40 bar, which decreases slightly on subsequent cycles. The reason for the rise in peak pressure during the first CAI cycle through the introduction of throttling is due to the decreased airflow resulting from throttling before the throttle settles at the WOT position. From Fig. 9, it can be seen that, when the throttle is opened from the 8 per cent throttle position (high-lift mode) to 100 per cent throttle position (low-lift mode), initially the airflow rises to $60 \mathrm{~g} / \mathrm{s}$ during the transition period and then evens out at $17.5 \mathrm{~g} / \mathrm{s}$. For opening from the 8 per cent throttle position to 20 per cent throttle position (Fig. 11), the airflow initially increases to $35 \mathrm{~g} / \mathrm{s}$ and levels out at $12.5 \mathrm{~g} / \mathrm{s}$.

\subsection{Effects of the throttle opening speed}

As discussed above, although setting the throttling opening position when transitioning from SI to CAI combustion avoided misfire, the variation in

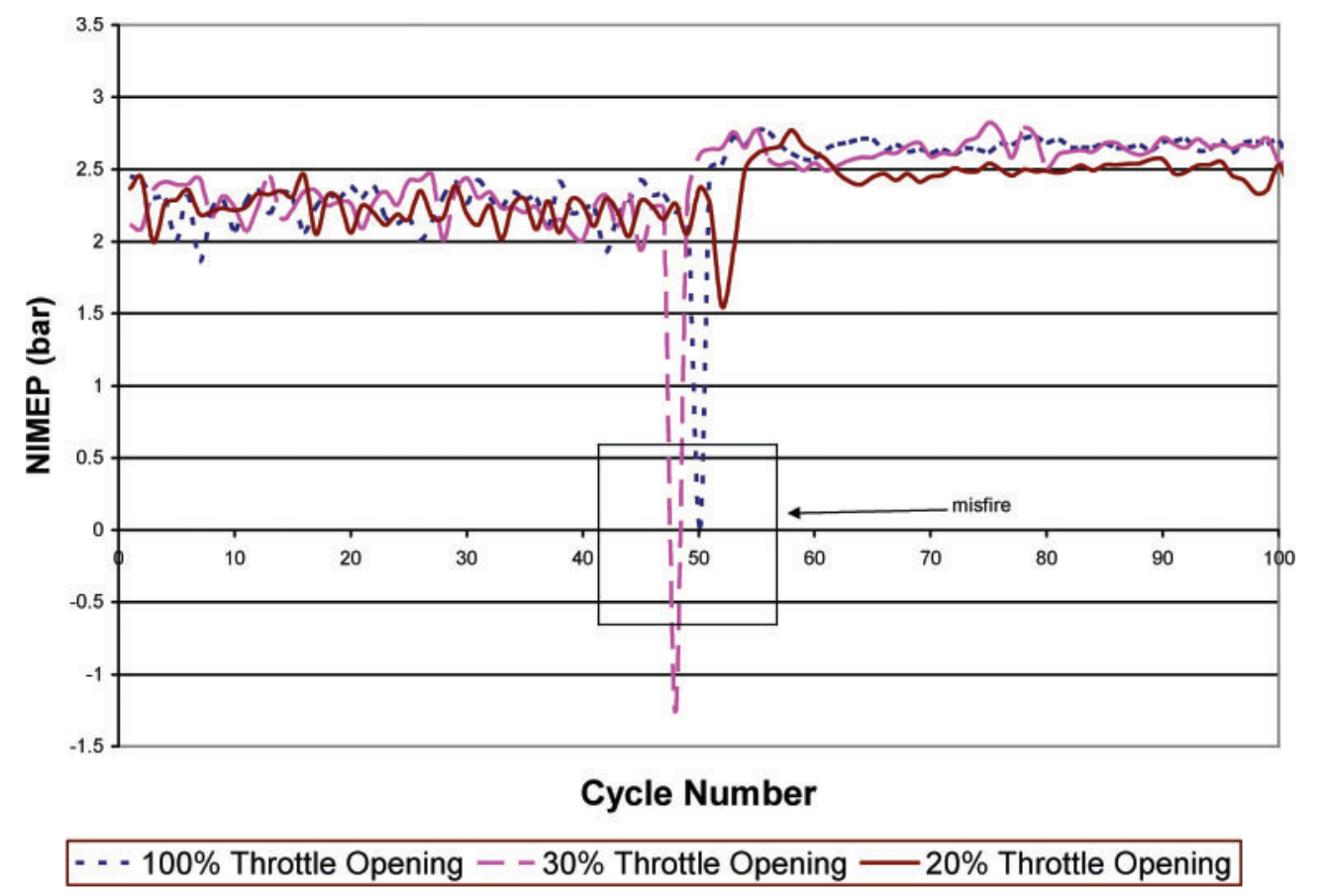

Fig. 8 Variation in the NIMEP at different throttle openings 


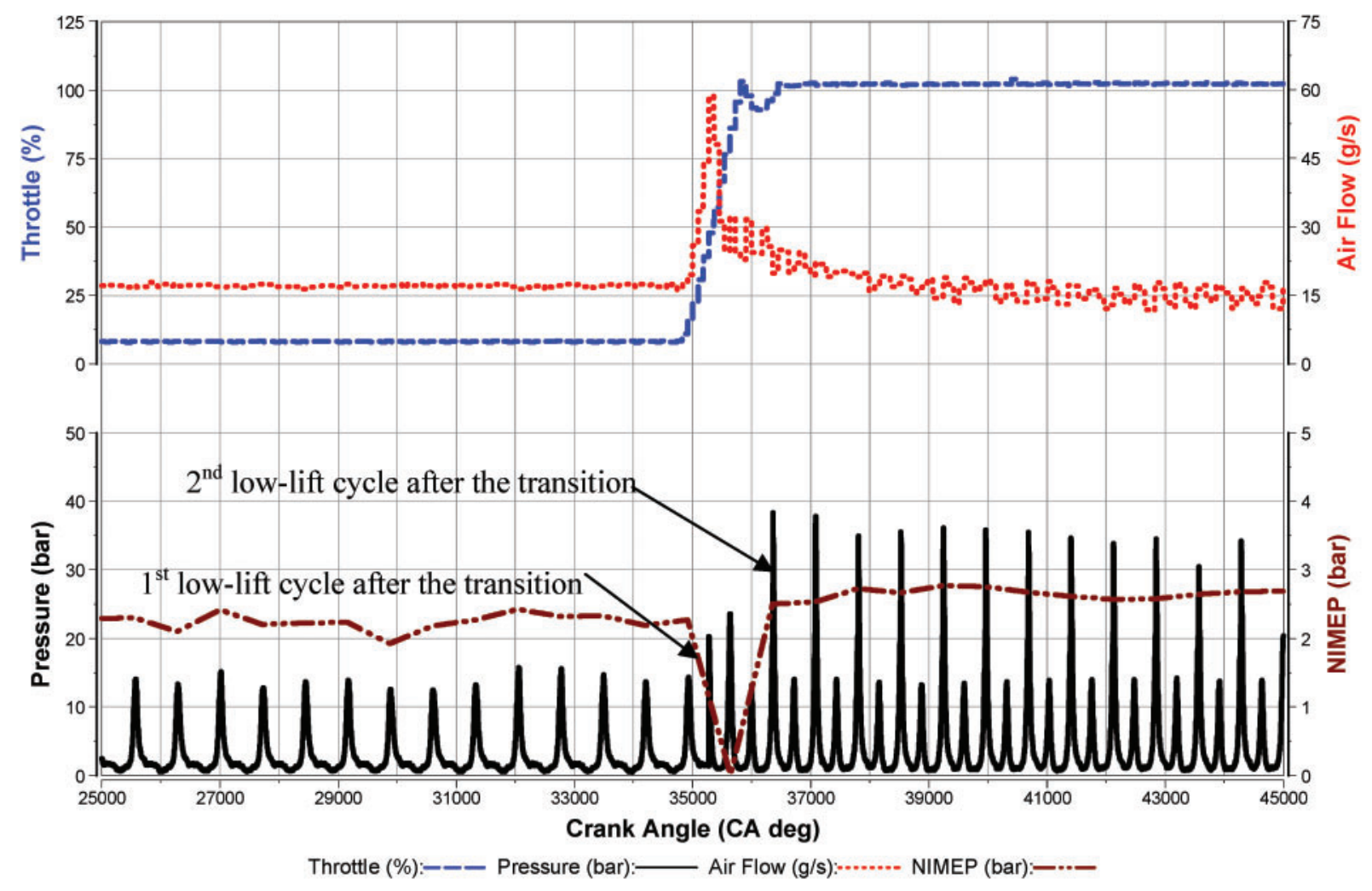

Fig. 9 Variations in the pressure, throttle, NIMEP, and air flow at 100 per cent throttle opening

the NIMEP was still about 1 bar. Therefore, it was of interest to investigate whether the variation in the NIMEP during a transition could be reduced. The step function, which is discussed in the engine setup section, was used to vary the rate at which the throttle was opened. As discussed, the air-to-fuel ratio becomes extremely lean in the first CAI cycle of transition when the throttle is opened to the WOT position. Therefore, to maintain stoichiometric conditions for the first CAI combustion cycle, the

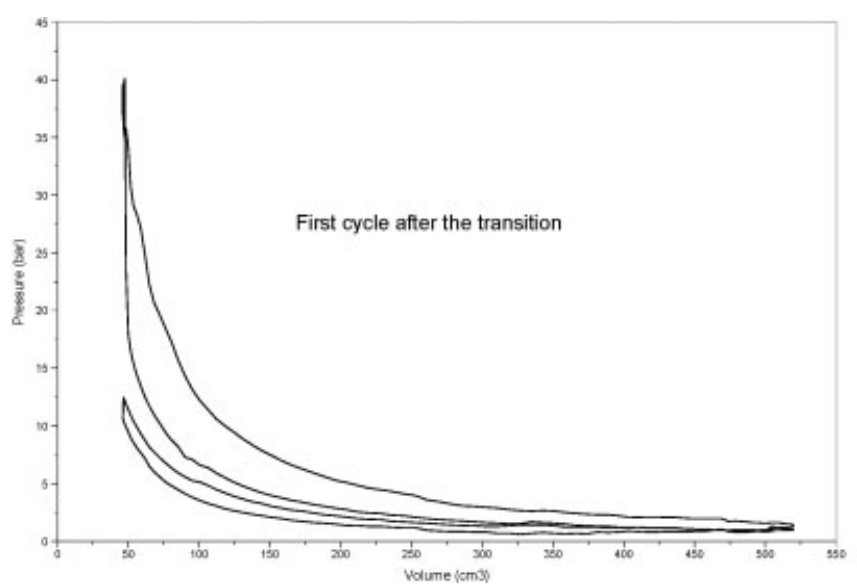

throttle is maintained in the initial throttle position for a determined switching time period corresponding to $t$ in Fig. 8. This switching time period is based on the time taken for the completion of each cycle at a particular engine speed; at $1500 \mathrm{r} / \mathrm{min}$, this switching time is taken to be $0.08 \mathrm{~s}$. Therefore, to understand the effects of the switching time further, three different values were used for the step function; namely, $0.08 \mathrm{~s}, 0.11 \mathrm{~s}$, and $0.13 \mathrm{~s}$. Figure 12 shows the effects of the throttle switching time on the NIMEP

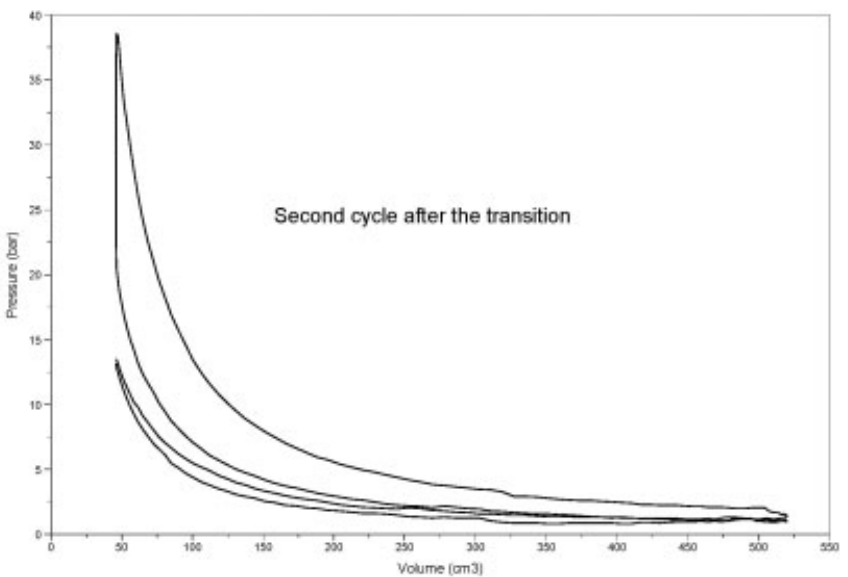

Fig. 10 Pressure-volume diagram for the first and second cycles of low-lift CAI operation after the transition 


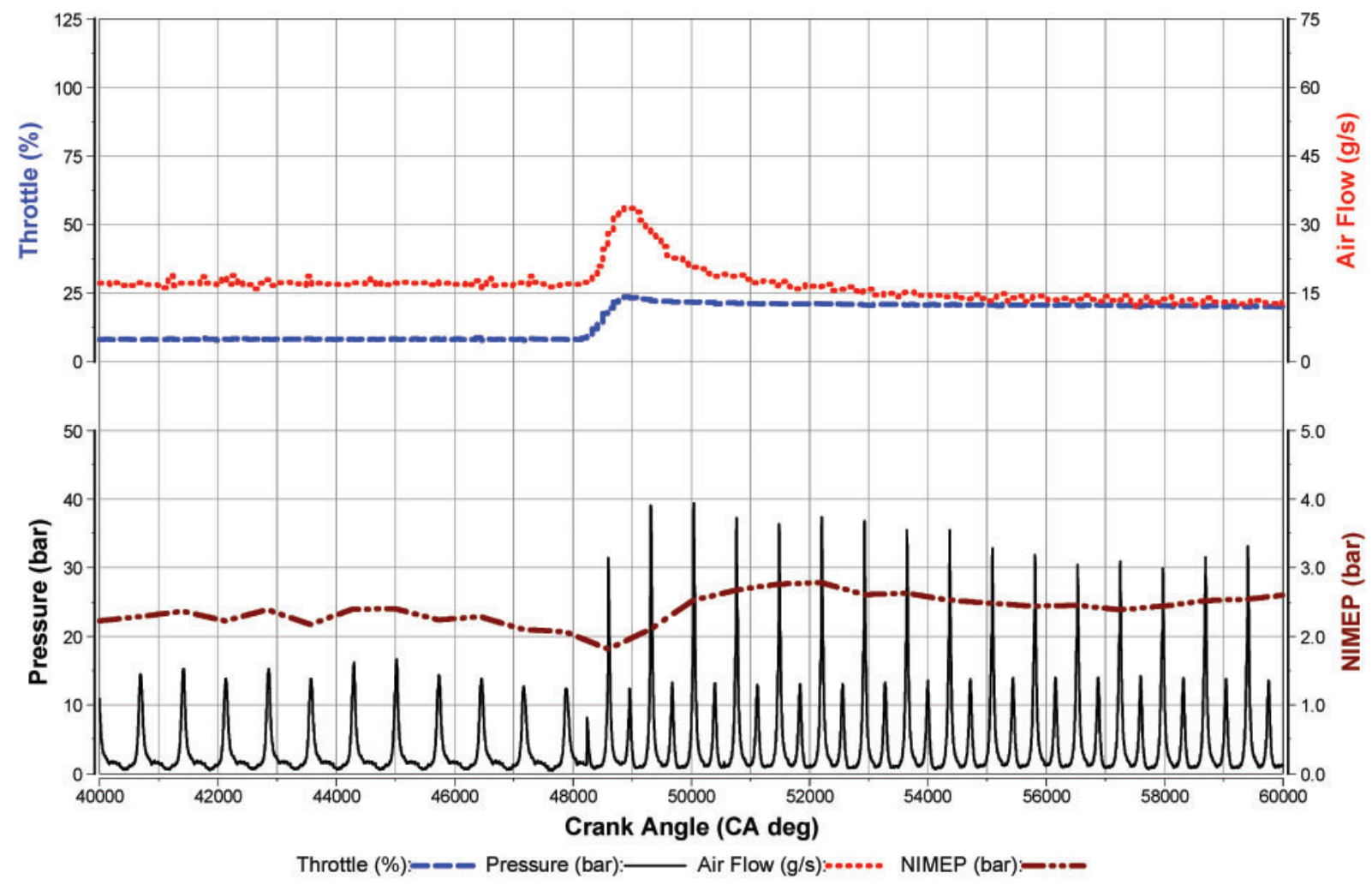

Fig. 11 Variations in the pressure, throttle, NIMEP, and airflow at 20 per cent throttle opening

variation, when the fixed throttle opening was 20 per cent of full airflow. At a switching time of $0.08 \mathrm{~s}$, the variation in the NIMEP is 0.65 bar; at a switching time of $0.13 \mathrm{~s}$, the variation drops to $0.35 \mathrm{bar}$, which is a significant improvement from a 1.5 bar drop noticed using no step function.

Figure 13 shows the variation in the pressure against the CA for 150 engine cycles at a switching

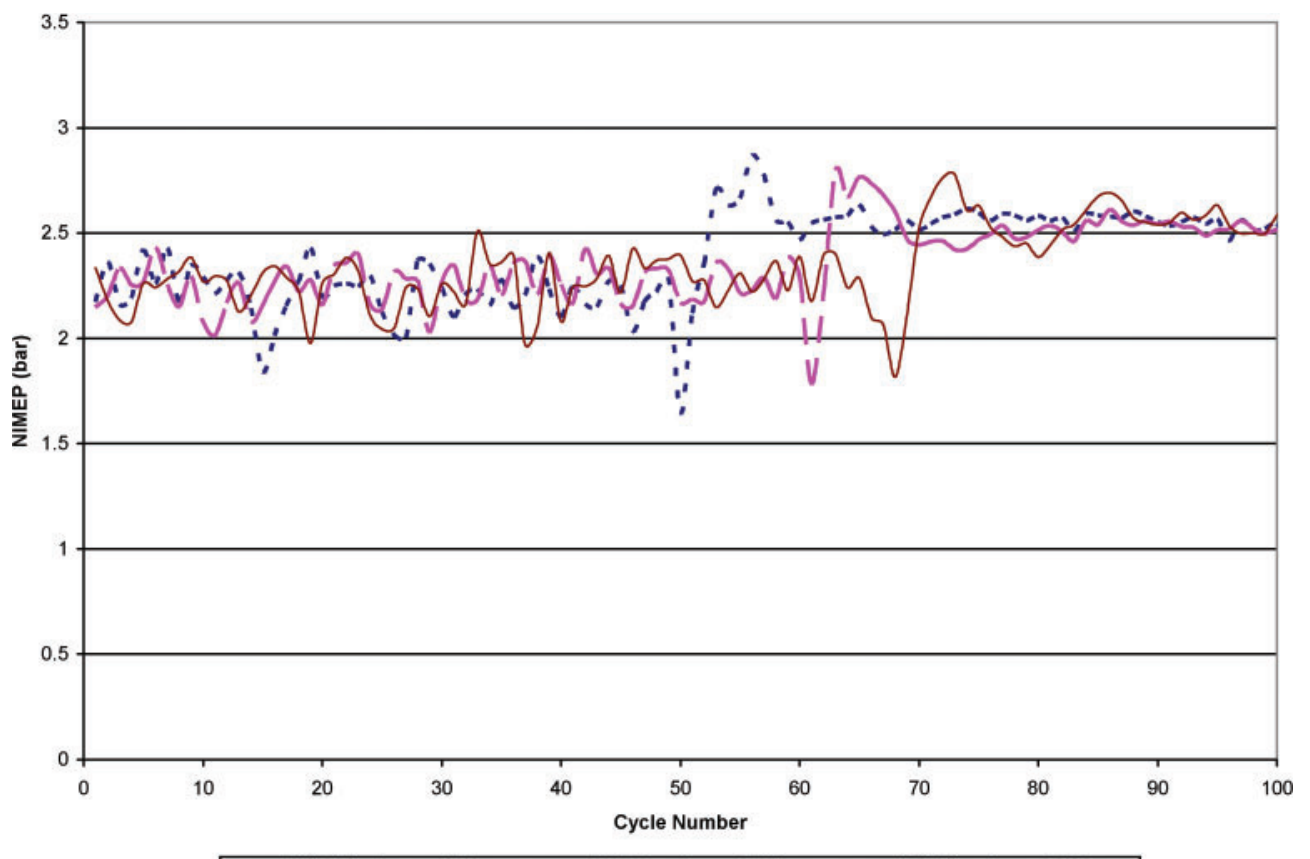

-- - Switching time $=0.08$ secs -- Switching time $=0.11$ secs - Switching time $=0.13$ secs

Fig. 12 Variation in the NIMEP at different switching times 


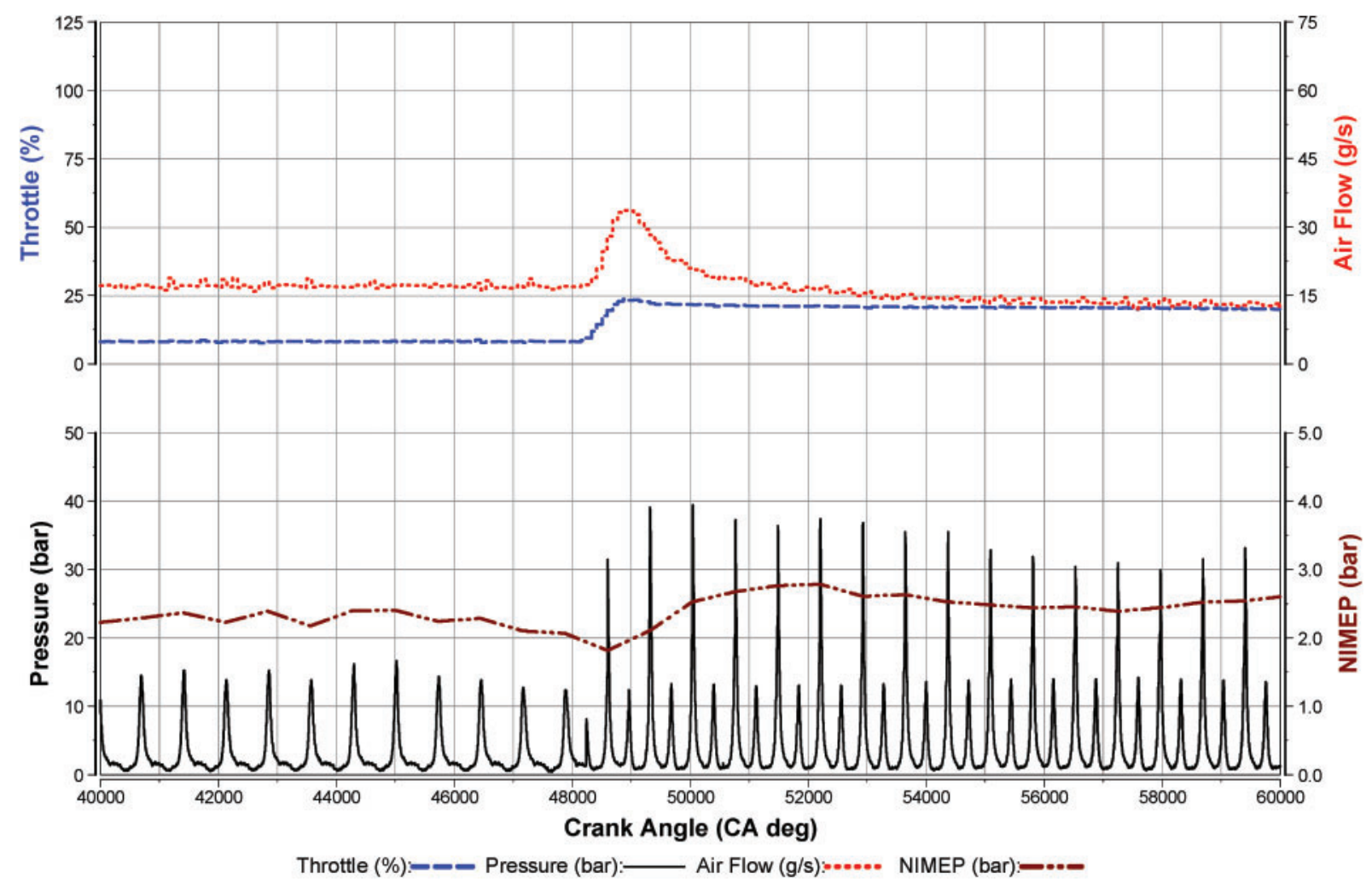

Fig. 13 Variations in the pressure, throttle, NIMEP, and airflow at 20 per cent throttle opening at switching time of $0.13 \mathrm{~s}$

time of $0.13 \mathrm{~s}$. It can be seen that, for the first CAI cycle, the peak pressure is $31 \mathrm{bar}$; for the second cycle, this increases to $39 \mathrm{bar}$. This indicates that, for the first CAI cycle, the air-to-fuel ratio is fairly lean and becomes richer for subsequent cycles. A reason for this is due to the 'overshoot' of the throttle, before correction is made for the correct position of the throttle through the control feedback. Figure 14 shows the instantaneous heat release rate against the CA. The heat release rate seems to be very advanced on the first CAI cycle, because of the hotter burned gas from the previous SI operation, and tends to retard gradually in subsequent cycles. Figure 15 shows the 50 per cent and 90 per cent MFB angles and the overall burn angle at a switching time of $0.13 \mathrm{~s}$. It can be observed that, for SI combustion, the 50 per cent and 90 per cent MFB angles are very retarded. On transition to CAI combustion, the 50 per cent and 90 per cent MFB angles move towards top dead centre. Furthermore, the burn angle for SI combustion is long, at $35^{\circ} \mathrm{CA}$, compared with about $8^{\circ} \mathrm{CA}$ for CAI combustion. It can be observed that for the first CAI cycle the burn angle is very short, whereas for the second CAI cycle the burn angle is longer. As discussed, the reason for this is due to hotter residuals from the previous SI operation.

\section{TRANSITION FROM CAI TO SI COMBUSTION}

\subsection{Introduction}

The CAI-SI transition involved the transition from CAI combustion at an advanced EVC at low lift to SI combustion at high lift. The valve timing used at low lift was a negative valve overlap configuration and SOI at very early intake. Speed was maintained at $1500 \mathrm{r} / \mathrm{min}$ and $\lambda$ at 1.0. The valve timing used in high-lift SI operation was positive valve overlap configuration and SOI at very early intake. Table 3 lists the parameters used during the transition.

It was found that the first cycle of SI combustion was unstable. This was initially considered to be caused by the lean mixture from the slowly closing throttle from WOT to 8 per cent required for SI combustion. In order to limit airflow into the combustion chamber for SI combustion, the throttle position for the last CAI cycle was reduced to 30 per cent. At 30 per cent opening position, CAI combustion proceeded as if at WOT because of the reduced valve lift. The throttle position was reduced to 30 per cent using the step function described in section 3.2. However, it was still found that there was misfire during the transition. Furthermore, different strategies were tested (Fig. 16); these mainly concerned a 


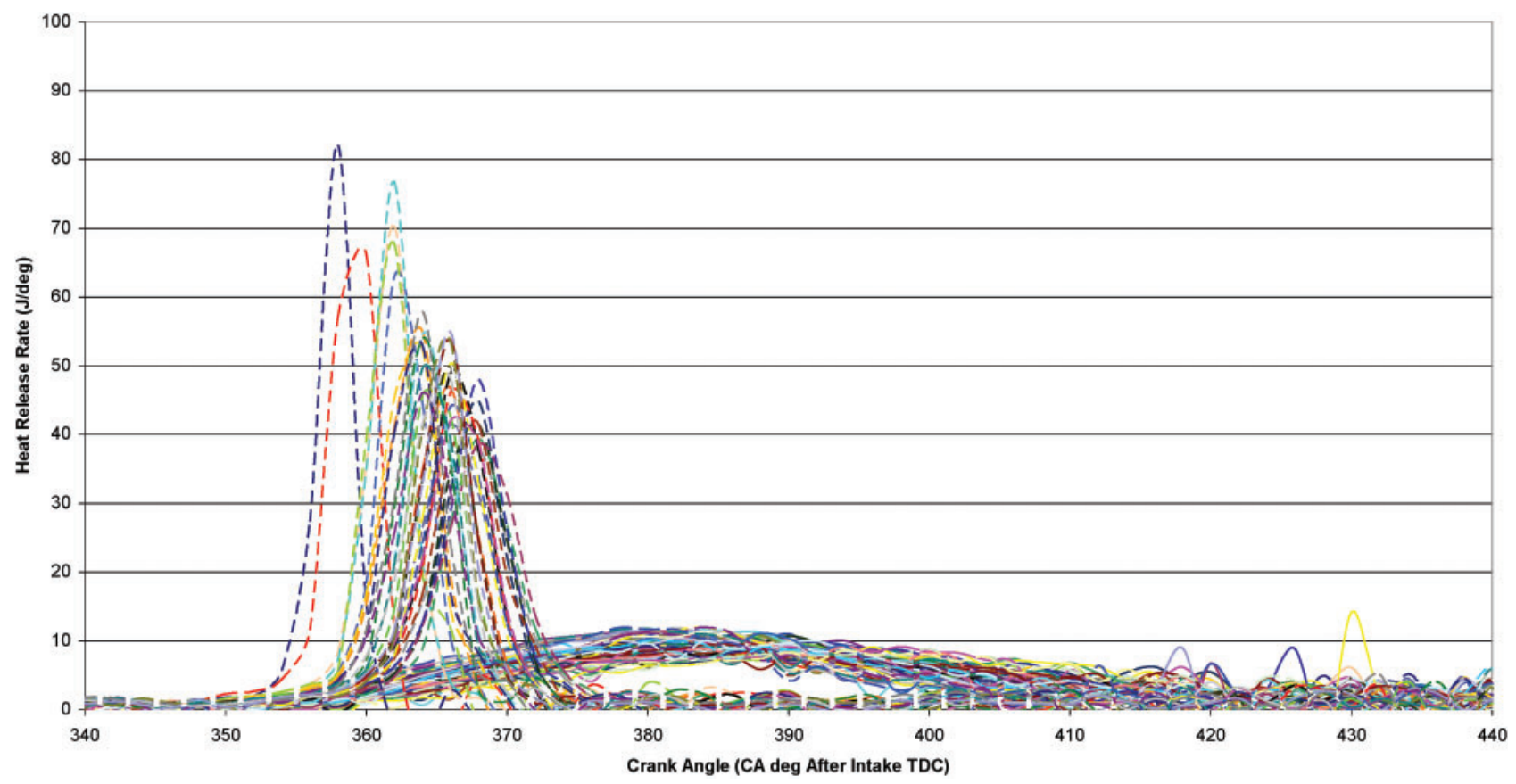

Fig. 14 Heat release at 20 per cent throttle opening and a switching time of $0.13 \mathrm{~s}$

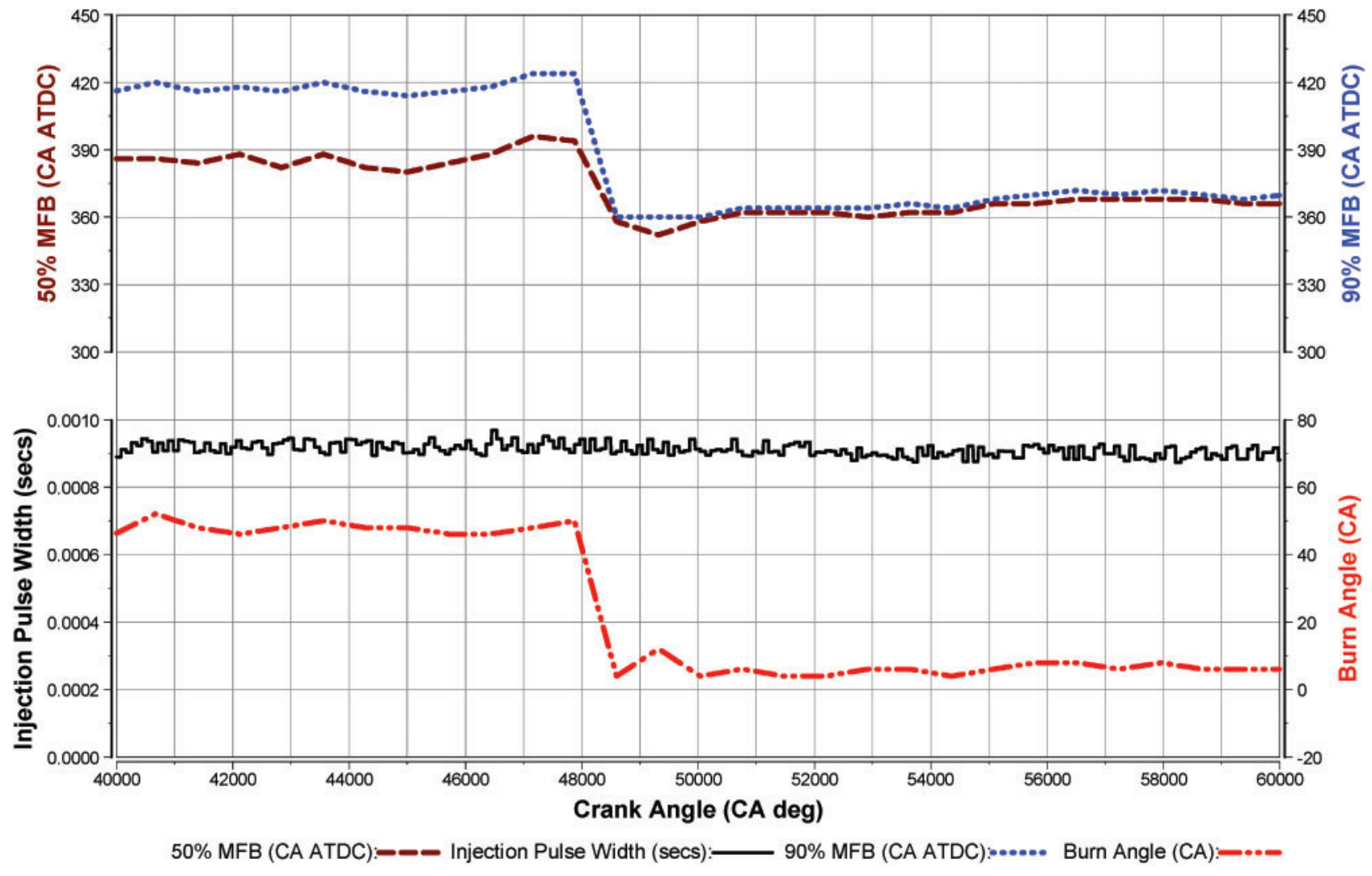

Fig. 1550 per cent and 90 per cent MFB and burn angles for 20 per cent throttle opening at a switching time of $0.13 \mathrm{~s}$ 
Table 3 List of conditions used for testing

\begin{tabular}{llllc}
\hline Mode & Valve timing & $\begin{array}{l}\text { Injection timing } \\
\left({ }^{\circ} \text { CA ATDC }\right)\end{array}$ & $\begin{array}{l}\text { Ignition timing } \\
\left({ }^{\circ} \text { CA ATDC }\right)\end{array}$ & $\begin{array}{l}\text { Speed } \\
(\mathrm{r} / \mathrm{min})\end{array}$ \\
\hline High lift & Positive valve overlap configuration & Very early intake & Varied & 1500 \\
Low lift & Negative valve overlap configuration & Very early intake & 340 & 1.0 \\
\hline
\end{tabular}

transition from 10 per cent, 15 per cent, 20 per cent, and 40 per cent throttle opening position during CAI operation to 8 per cent throttle opening position in high-lift operation. These strategies did not appear to reduce misfire during the transition, as seen from Fig. 16. For all cases, there is a drop in the NIMEP, indicating a misfire during the transition.

\subsection{Effects of the start-of-fuel-injection timing on the transition}

It was realized that a transition from an advanced low-lift EVC led to misfire. This is due to the large percentage of trapped residuals at advanced EVC. During the first cycle of SI combustion at high lift, a large percentage of residuals remain in the cylinder from CAI operation, leading to misfire. Therefore, a strategy was developed in which EVC timing during CAI combustion was retarded. Furthermore, it was reasoned that a transition from a retarded SOI would allow stratified mixing, which would lead to fuel-rich pockets that would give a better site for combustion. Therefore, a strategy was developed that involved a transition from a retarded low-lift EVC timing and at a retarded SOI timing. SOI was varied to early-intake, mid-intake, and late-intake injection.

Figure 17 shows the variation in the NIMEP during a transition for SOI at early, mid, and late injection. It can be seen that for transition at early SOI and mid-SOI at a retarded EVC for low-lift operation, misfire is avoided and the transition results in very little variation in the NIMEP from low-lift operation to high-lift operation. For transition at late SOI, misfire occurs; this is because the injection timing is too late for auto-ignition to start and, hence, there is consequent misfire.

Figure 18 shows the heat release rate $(\mathrm{J} / \mathrm{deg})$ against CA at mid-SOI; it can be seen that there is no misfire during the transition. Furthermore, there is little variation in combustion phasing for both CAI and SI combustion.

\subsection{Effects of the transition at different loads}

One of the advantages of SI combustion is that a wide load range can be achieved. Therefore, it was of interest to investigate the transition from CAI to SI combustion at different loads. Three different load

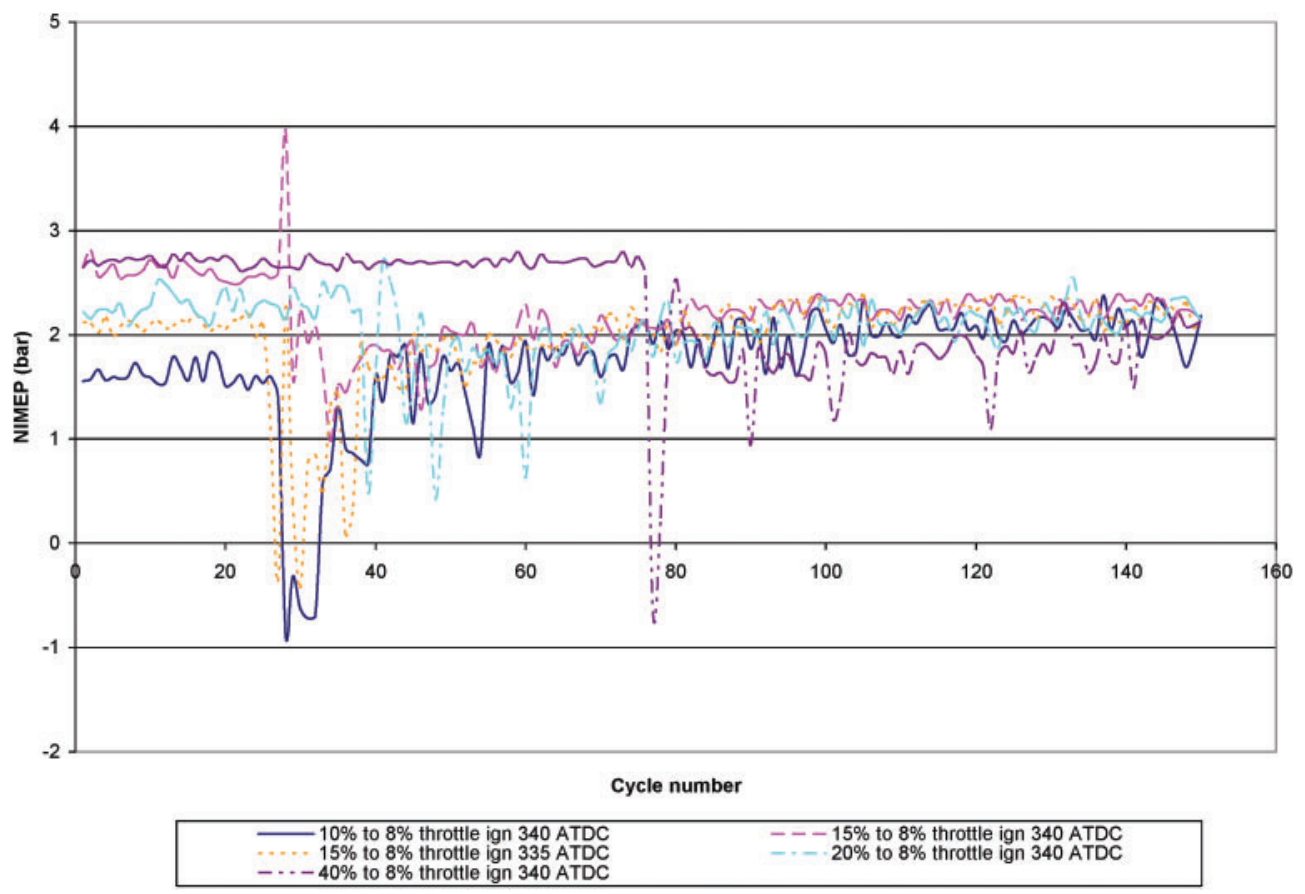

Fig. 16 CAI-SI transition for different throttle positions and ignition timings 


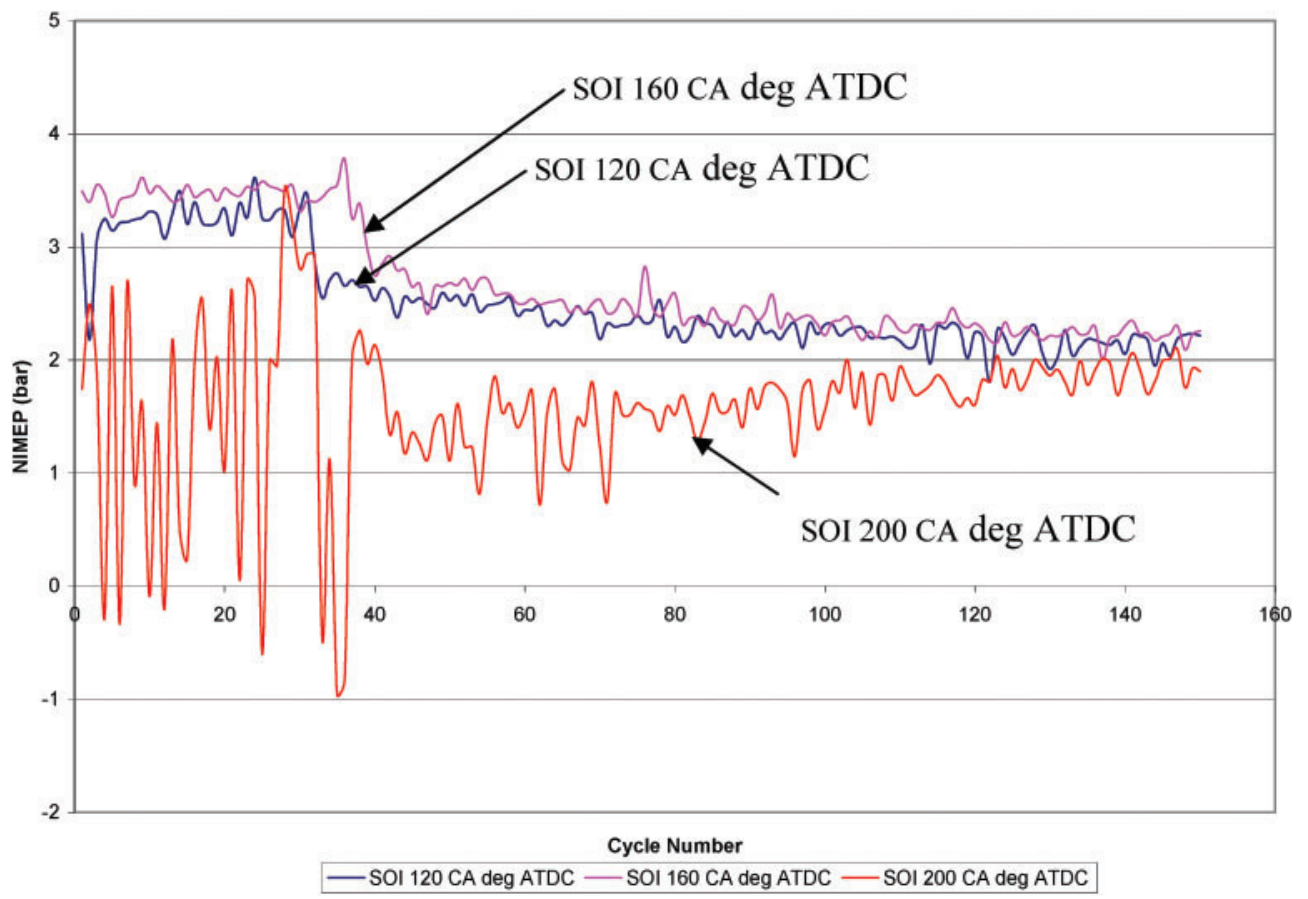

Fig. 17 Effects of SOI timing and retarded CAI EVC on the CAI-SI transition

tests were conducted, transitions from approximately 3.5 bar load during CAI combustion to $2.25 \mathrm{bar}$, 3.25 bar, and 4.25 bar NIMEP load during high-lift SI combustion. Different loads were achieved during high-lift SI operation by varying the throttle position. The throttle positions were 8 per cent, 15 per cent, and 20 per cent for loads of $2.25 \mathrm{bar}, 3.25 \mathrm{bar}$, and 4.25 bar consecutively. Table 4 summarizes the different load cases. The valve timing for low-lift CAI operation was undertaken at a reduced negative valve overlap configuration and mid-SOI. For high-lift SI operation, the valve timing was set in a positive valve overlap

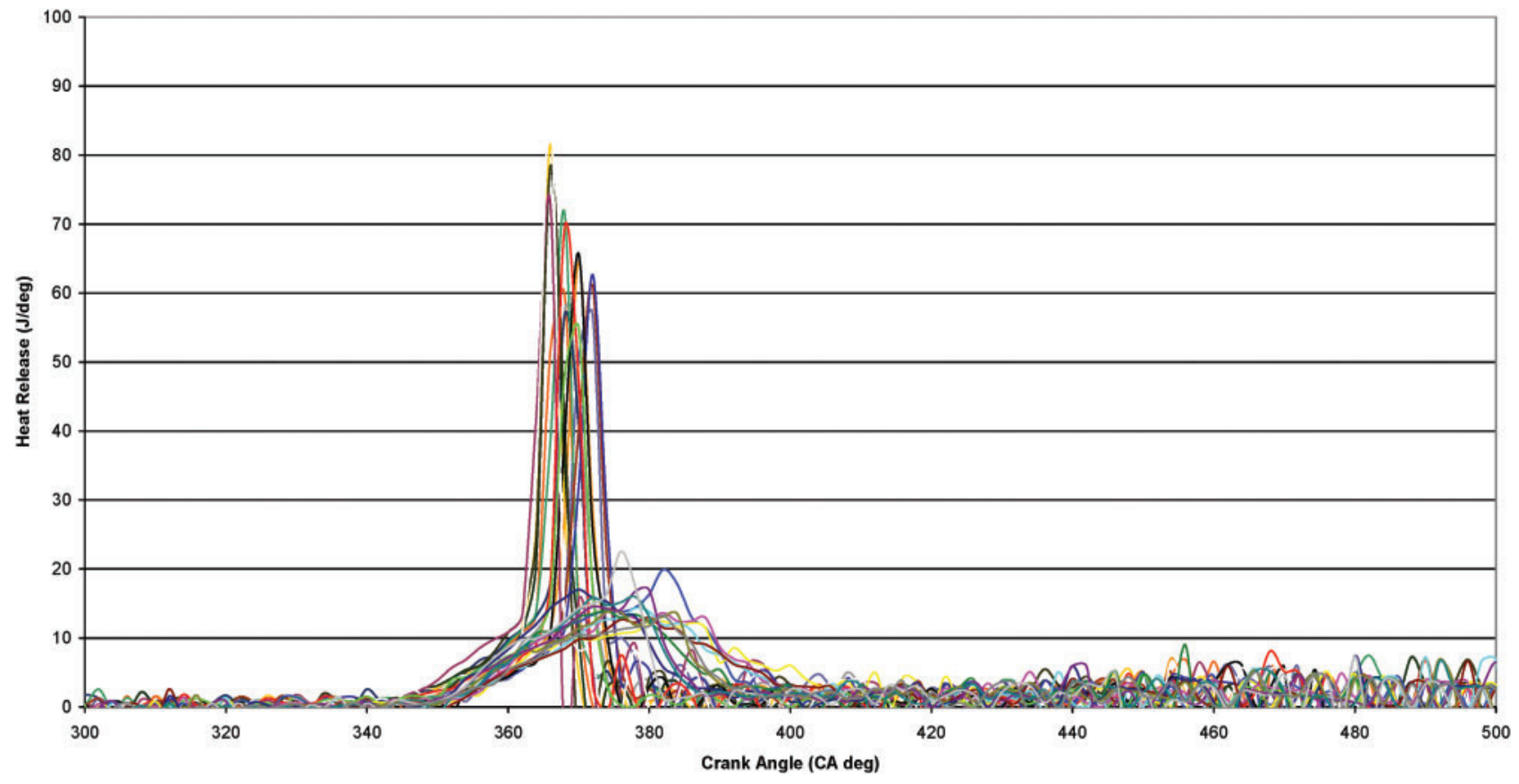

Fig. 18 Heat release against CA for SOI at $160^{\circ}$ CA ATDC and retarded CAI EVC for the CAI-SI transition 
Table 4 Throttle position and engine load (NIMEP) for case 1 , case 2 , and case 3

\begin{tabular}{lll}
\hline Case & Throttle position (\%) & $\begin{array}{l}\text { Load (NIMEP) for high- } \\
\text { lift SI (bar) }\end{array}$ \\
\hline 1 & 8 & 2.25 \\
2 & 10 & 3.25 \\
3 & 15 & 4.25 \\
\hline
\end{tabular}

configuration and very early SOI. Table 5 summarizes the test conditions used during the transition. It was found that transition could be achieved with no resulting misfire at different loads.

Figure 19 shows the variation in the NIMEP for 100 cycles for case 1 , case 2 , and case 3 . Figures 20, 21 , and 22 shows the throttle position, airflow rate, pressure and NIMEP for case 1, case 2, and case 3, respectively. From case 2 and case 3, it can be seen that there is a fluctuation in the NIMEP; the NIMEP varies by 0.9 bar and 0.5 bar during the first high-lift SI operation. This variation occurs because trapped residuals from CAI combustion remain in the cylinder for SI combustion. As a consequence, the closed-loop feedback control will vary $\lambda$ in order to achieve a stoichiometric $\lambda$. However, many cycles pass before $\lambda$ is corrected and the NIMEP stops fluctuating wildly.

\section{SUMMARY AND CONCLUSION}

A Jaguar 3.0 1 gasoline engine with DI and CPS capabilities was successfully commissioned and operated. Furthermore, successful transition was carried out from high-lift SI combustion to low-lift CAI combustion.

It was found that the control strategy had to be tuned in order to realize a successful transition from SI mode to CAI mode. First, the control program was modified so that two different sets of parameters, namely ignition timing, injection timing, and valve timing, could be preset: one for SI high-lift mode and one for low-lift CAI mode. Hence, when a transition was undertaken, the parameters would change instantly.

However, it was found that, during a transition from SI mode to CAI mode, the air-to-fuel ratio would become extremely lean because at high lift a large volume of air would be inducted; this volume of excess air would remain in lagging firing cylinders during the transition. A strategy was employed where the throttle opening percentage was limited during the first cycle of transition. It was found that by limiting the throttle to 20 per cent in the first transition cycle it was possible to avoid misfire.

It was found that the throttle opening speed could be controlled using a 'step function'. The function took into consideration the time at which the throttle was kept in the initial position, and also the rate at which to change the throttle position. The 'step function' was expressed in terms of the 'switching time'. It was found that, at a switching time of $0.13 \mathrm{~s}$ for the given experimental conditions, the NIMEP varied by 0.35 bar during the transition. It is apparent that, for profile switching, the step function and switching parameters have to be tuned for transition at different speeds and loads.

Transition from CAI to SI combustion was also investigated. It was found that reducing the throttle opening in the last CAI cycle before the transition did not prevent misfire. Also varying the ignition timing for SI combustion also did not prevent misfire.

During the first cycle of SI combustion at high lifts, a large percentage of trapped residuals remain in the cylinder from CAI operation, leading to misfire. Therefore, a strategy was developed whereby the EVC timing was retarded and, hence, the percentage of trapped residuals was reduced. It was envisaged that the EVC timing would be retarded in the last cycle of CAI operation before the transition. It was found that misfire was avoided and a smooth transition could be undertaken. Transition from different CAI load points to SI load points was investigated. It was found that, again, transition occurred without misfire. However, the NIMEP values tended to fluctuate for the first 50 high-lift SI cycles before the closed-loop feedback had corrected the air-tofuel ratio.

\section{ACKNOWLEDGEMENTS}

The authors would like to thank the Engineering and Physical Science Research Council of the UK and Jaguar Cars Limited for their financial support

Table 5 List of conditions used for transitions at different loads

\begin{tabular}{|c|c|c|c|c|c|}
\hline Mode & Valve timing & $\begin{array}{l}\text { Injection timing } \\
\left({ }^{\circ} \text { CA ATDC) }\right.\end{array}$ & $\begin{array}{l}\text { Ignition timing } \\
\left({ }^{\circ} \mathrm{CA} \text { ATDC }\right)\end{array}$ & $\begin{array}{l}\text { Speed } \\
(\mathrm{r} / \mathrm{min})\end{array}$ & $\lambda$ \\
\hline High lift & Positive valve overlap configuration & Very early intake & 340 & 1500 & 1.0 \\
\hline Low lift & Negative valve overlap configuration & Mid-intake & 340 & 1500 & 1.0 \\
\hline
\end{tabular}




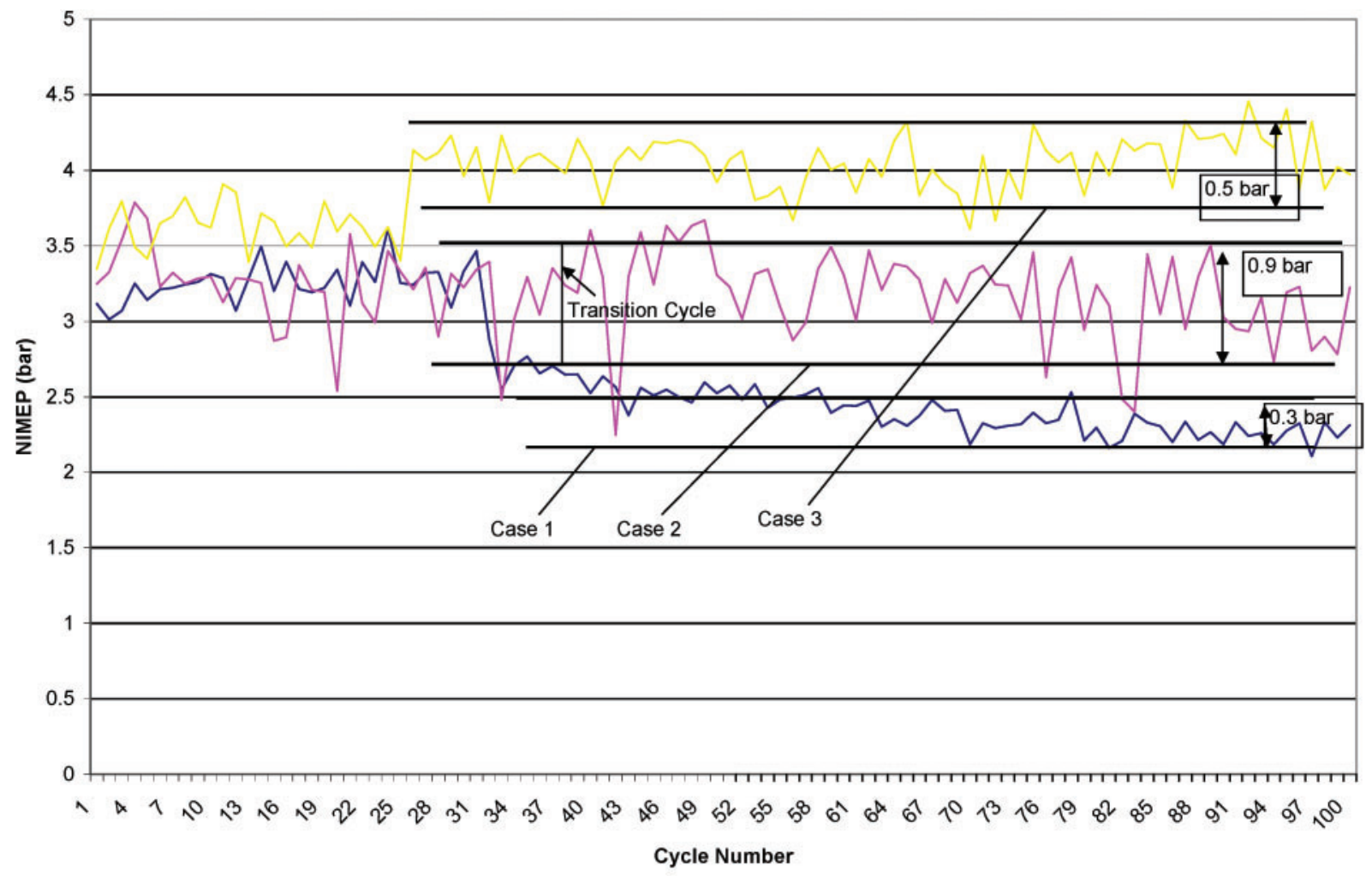

Fig. 19 CAI-SI transition at different loads for SOI at $160^{\circ}$ CA ATDC and retarded CAI EVC

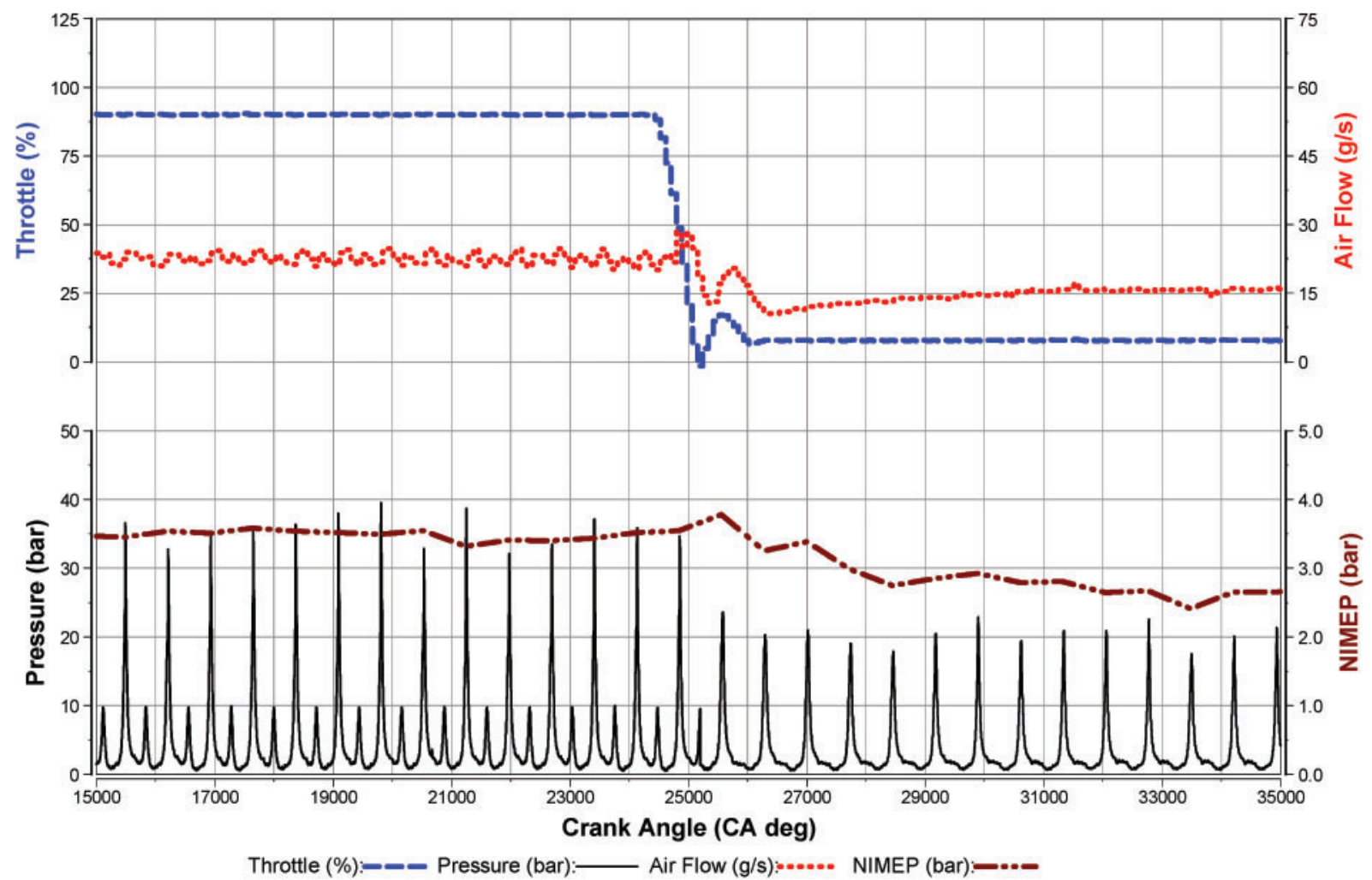

Fig. 20 Pressure, NIMEP, and throttle response for transition case 1 for SOI at $160^{\circ}$ CA ATDC and retarded CAI EVC 


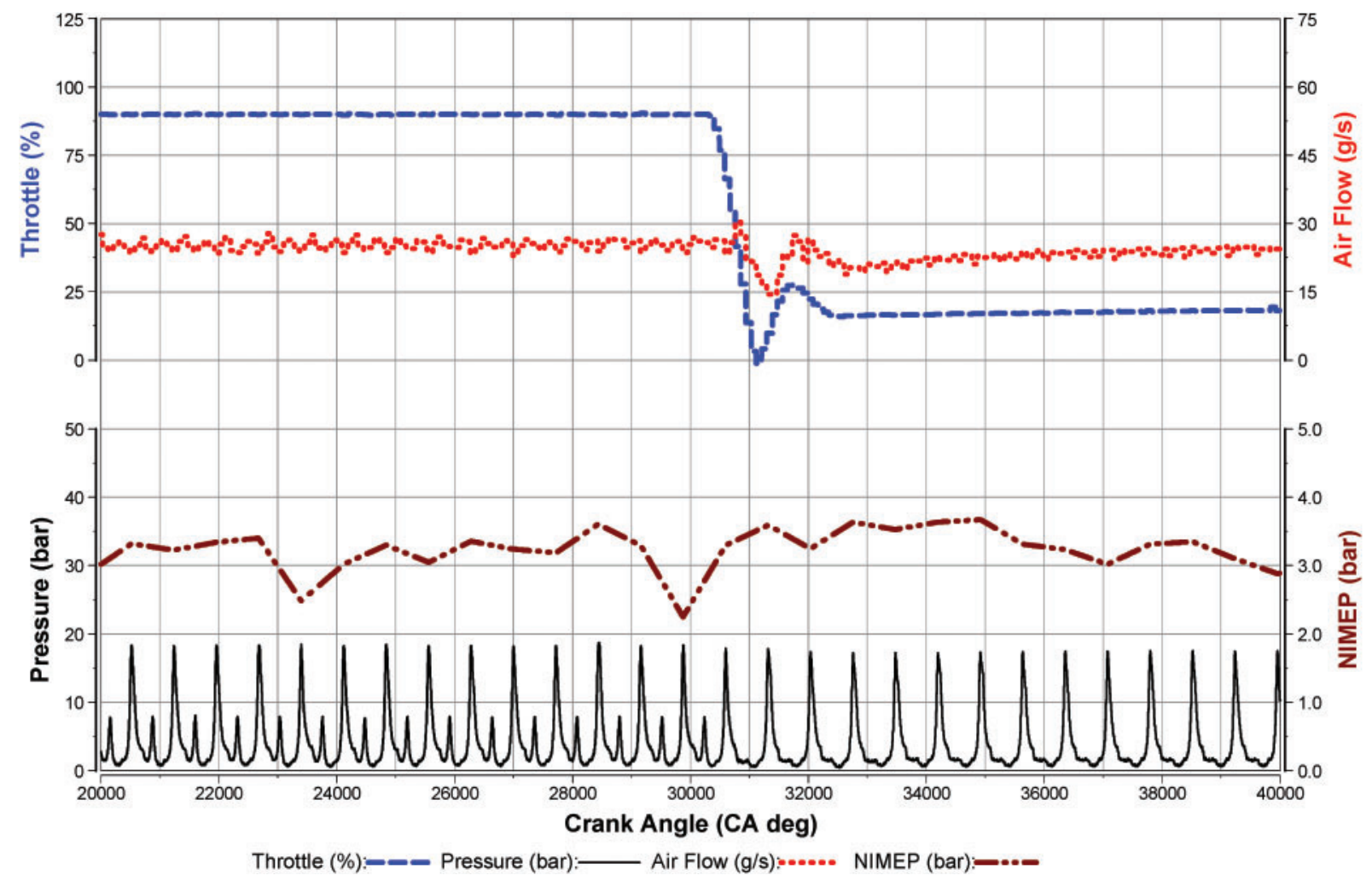

Fig. 21 Pressure, NIMEP, and throttle response for transition case 2 for SOI at $160^{\circ}$ CA ATDC and retarded CAI EVC

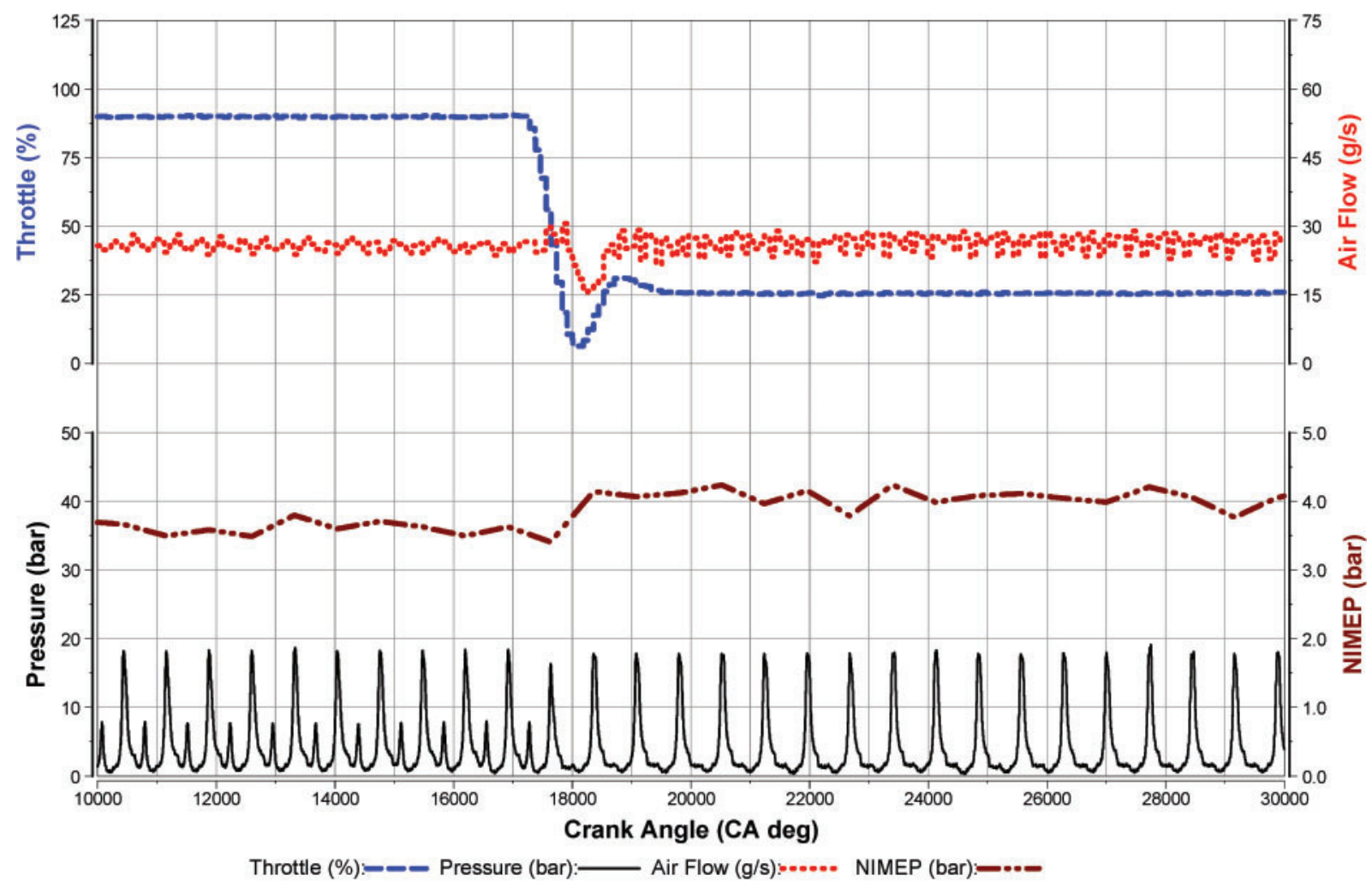

Fig. 22 Pressure, NIMEP, and throttle response for transition case 3 for SOI at $160^{\circ}$ CA ATDC and retarded CAI EVC 
and for providing the engine hardware. The present authors would also like to also express gratitude to Dr Trevor Wilson for all his technical support during the commissioning of the engine, and to Andy, Clive, Ken, and John, the technicians at the Engines Laboratory, Brunel University, for their invaluable support.

\section{REFERENCES}

1 Li, J., Zhao, H., and Ladommatos, N. Research and development of controlled auto-ignition (CAI) combustion in a 4-stroke multi-cylinder gasoline engine. SAE paper 2001-01-3608, 2001.

2 Aoyama, T., Hattori, Y., Mizuta, J., and Sato, Y. An experimental study on premixed-charge compression ignition gasoline engine. SAE paper 960081, 1996.

3 Willand, J., Nieberding, R. G., Vent, G., and Enderle, C. The knocking syndrome - its cure and its potential. SAE paper 982483, 1998.

4 Urushihara, T., Hiraya, K., Kakuhou, A., and Itoh, T. Expansion of HCCI operating region by the combination of direct fuel injection, negative valve overlap and internal fuel reformation. SAE paper 2003-01-0749, 2003.

5 Yamaoka, S., Kakuya, H., Nakagawa, S., Nogi, T., Shimada, A., and Kihara, Y. A study of controlling the auto-ignition and combustion in a gasoline HCCI engine. SAE paper 2004-01-0942, 2004.

6 Oakley, A., Zhao, H., and Ladommatos, N. Experimental studies on controlled auto-ignition (CAI) combustion of gasoline in a 4-stroke engine. SAE paper 2001-01-1030, 2001.

7 Yap, D., Megaritis, A., Wyszynski, M. L., and Xu, H. Effect of inlet valve timing on boosted gasoline HCCI with residual gas trapping. SAE paper 200501-2136, 2005.

8 Lavy, J., Dabadie, J. C., Angelberger, C., Duret, P., Willand, J., Juretzka, A., Schaflein, J., Ma, T., Lendresse, Y., Satre, A., Schulz, C., Kramer, H., Zhao, H., and Damiano, L. Innovative ultra-low $\mathrm{NO}_{x}$ controlled auto-ignition combustion process for gasoline engines: the 4-SPACE project. SAE paper 2000-01-1873, 2000.

9 Wang, Z., Wang, J., Shuai, S., Tian, G., An, X., and Ma, Q. Study of the effect of spark ignition on gasoline HCCI combustion. Proc. IMechE, Part D: J. Automobile Engineering, 2006, 220(6), 817-825.

10 Onishi, S., Jo, S. H., Shoda, K., Jo, P. K., and Kato, S. Active thermo-atmospheric combustion (ATAC) - a new combustion process for internal combustion engines. SAE paper 790501, 1979.

11 Ishibashi, Y. and Asai, M. Improving the exhaust emissions of two-stroke engines by applying the activated radical combustion. SAE paper 960742, 1996.
12 Xu, H., Williams, A., Fu, H., Wallace, S., Richardson, S., and Richardson, M. Operating characteristics of a homogeneous charge compression ignition engine with cam profile switching-simulation study. SAE paper 2003-01-1859, 2003.

13 Tian, G., Wang, Z., Ge, Q., Wang, J., and Shuai, S. J. Mode switch of SI-HCCI combustion on a GDI engine. SAE paper 2007-01-0195, 2007.

14 Milovanovic, N., Blundell, D., Gedge, S., and Turner, J. SI-HCCI-SI mode transition at different engine operating conditions. SAE paper, 2005-010156, 2007.

15 Zhao, H. HCCI and CAI engines for the automotive industry, 2007, pp. 185-195 (Woodhead Publishing Abington, Cambridge).

16 Koopmans, L., Strom, H., Lundgren, S., Backland, O., and Denbratt, I. Demonstrating a SI-HCCI-SI mode change on a Volvo 5-cylinder electronic valve control engine. SAE paper 2003-01-0753, 2003.

17 Zhang, Y., Xie, H., Zhou, N., Chen, T., and Zhao, H. Study of SI-HCCI-SI transition on a port fuel injection engine equipped with 4VVAS. SAE paper 2007-01-0199, 2007.

18 Cairns, A. and Blaxill, H. The effects of two-stage cam profile switching and external EGR on SI-CAI combustion transitions. SAE paper 2007-01-0187, 2007.

\section{APPENDIX}

\section{Notation}

$\begin{array}{ll}\text { ATDC } & \text { after top dead centre } \\ \text { BMEP } & \text { brake mean effective pressure } \\ \text { CA } & \text { crank angle } \\ \text { CAI } & \text { controlled auto-ignition; see also } \\ & \text { HCCI } \\ \text { CPS } & \text { cam profile switching } \\ \text { DI } & \text { direct injection } \\ \text { EGR } & \text { exhaust gas recirculation } \\ \text { EVC } & \text { exhaust valve closing } \\ \text { HCCI } & \text { homogeneous charge compression } \\ & \text { ignition } \\ \text { IMEP } & \text { indicated mean effective pressure } \\ \text { IVO } & \text { intake valve opening } \\ \text { MFB } & \text { mass fraction burned } \\ \text { NIMEP } & \text { net indicated mean effective pressure } \\ \text { NO } & \text { oxides of nitrogen } \\ \text { SI } & \text { spark ignition } \\ \text { SOI } & \text { start of ignition } \\ \text { TDC } & \text { top dead centre } \\ \text { WOT } & \text { wide-open throttle } \\ \text { VVT } & \text { variable valve timing } \\ & \end{array}$

